\title{
Knowledge of glaucoma and associated factors among adults in Gish Abay town, Northwest Ethiopia
}

\author{
Zewdu Yenegeta ${ }^{1 *}$, Ayanaw Tsega ${ }^{2}$, Yezinash Addis $^{2}$ and Fisseha Admassu ${ }^{3}$
}

\begin{abstract}
Background: Glaucoma is a global public health problem and it is the leading cause of irreversible blindness worldwide. Even though public knowledge of glaucoma is a key for early case identification and prevention of blindness, it is unknown in the study area, making provision of interventions difficult. Therefore, this study was intended to assess knowledge of glaucoma and associated factors among adults in Gish Abay town, Northwest Ethiopia, 2018.
\end{abstract}

Methods: A Community based cross - sectional design study with systematic random sampling technique was used to select 630 adults. The study was conducted from April to May, 2018. Data was entered into Epi Info version 7 and was analysed by Statistical Package for Social Sciences version 23. Binary logistic regression model and adjusted odds ratio with $95 \%$ confidence level was used to identify the significant factors associated with knowledge of glaucoma. Variables with P-value $\leq 0.05$ was considered statistically significant.

Results: About 594 adults were participated with a response rate of $94 \%$. Above half of (52\%) the participants were females with median age of 28 years. The proportion of good knowledge was demonstrated in $16.8 \%$ [95\% Cl; 14.0, 19.9]. Educational status: primary education [AOR; 2.89: 1.41, 5.90], secondary education [AOR; 3.03: 1.47, 6.24] college and above [AOR; 5.18: 2.21, 12.13], history of eye examination [AOR; 6.52: 3.37, 12.63]; family history of glaucoma [AOR; 12.08: 4.13, 35.30] and higher income level [AOR; 3.11: 1.55, 6.25] were positively associated with good knowledge of glaucoma.

Conclusions: The proportion of good knowledge of glaucoma was low. Higher educational status, positive family history of glaucoma, eye examination and higher income level were significantly associated with knowledge of glaucoma.

Keywords: Knowledge, Glaucoma, Associated factors, Gish Abay, Ethiopia

\section{Background}

Glaucoma is a group of disease characterized by progressive optic neuropathy and visual field defect [1]. Fifteen percent's of worlds blindness is attributed due to glaucoma and around 600,000 people go blind annually [2]. In 2013, the number of people with glaucoma worldwide was estimated to be 64.3 million [3]. This is expected to raise to 76 million in 2020 and 111 million in 2040 [3]. Africa accounts for $15 \%$ worlds blindness burden due to

\footnotetext{
* Correspondence: zewduyenegeta@gmail.com

${ }^{1}$ Department of Ophthalmology, St. Paul's Hospital Millennium Medical

College, Addis Ababa, Ethiopia

Full list of author information is available at the end of the article
}

glaucoma [3]. In Ethiopia, glaucoma is the fifth common cause of blindness which results an irreversible sight loss for an estimated 62,000 Ethiopians $[4,5]$.

The increasing prevalence of glaucoma is expected to cause a significant economic burden and poor quality of life [6-8].

High glaucoma morbidity among some African communities may be attributed to low trained professionals, low awareness, under-utilization of eye care service as well as limited availability of treatment procedures [9-11]. It has been estimated that half of glaucoma patients are already blind in at least one eye in presentation in Africa [12]. The situation is worse in sub Saharan Africa where it is further

(C) The Author(s). 2020 Open Access This article is distributed under the terms of the Creative Commons Attribution 4.0 International License (http://creativecommons.org/licenses/by/4.0/), which permits unrestricted use, distribution, and 
compounded by poor awareness and knowledge of glaucoma in the region [13].

Raising public awareness early and creating knowledge of glaucoma is a key means of addressing its devastating consequences by enhancing people alertness, increasing regularly eye screening practice and increase the chance of identifying undetected cases [5]. Contrary to this, lack of awareness of glaucoma appeared to influence self-care practices [14].

Poor public awareness, knowledge and misconceptions associated with glaucoma is challenge for public health professionals [14].

According to different literatures reviewed educational status [15-17], positive family history of glaucoma [16, $18,19]$, history of eye examination [10, 12, 17], type of occupation (medical profession) [10, 20], positive glaucoma status [16], having a chronic disease like diabetes mellitus or hypertension or both [19] and high income level $[15,20-23]$ were positively associated with knowledge of glaucoma.

It is known that awareness leads to knowledge and knowledge to behavior [24]. However, published evidences indicates that knowledge about glaucoma is limited across the globe [14-16, 24, 25]. Therefore, this study is intended to fill this gap while serving as a baseline information for policy makers to evaluate intervention programs and to design future programs and techniques for effective health education based on identified factors.

\section{Methods}

\section{Study population and study design}

A community based cross-sectional design study was conducted in Gish Abay town. It is found in West Gojjam administrative zone. The capital of Sekela, Gish Abay, located $463 \mathrm{~km}$ from Addis Ababa. Gish Abay has 2 Keeble's with 8883 households. This study was conducted between April to May, 2018. All adults $\geq 18$ years were included in the study.

\section{Sample size determination}

Sample size was determined separately for knowledge and the associated factors to address the objectives. The sample size was determined by single population proportion formula with the assumption of $95 \%$ confidence level $(\mathrm{Z} \square / 2=1.96)$, $4 \%$ maximum allowable error $(\mathrm{w}), 5 \%$ non-response rate. The sample size for knowledge taking the proportion, $p=49.6$ for good and 50.4 for poor [17] was 630 for both.

\section{Sampling procedure}

Systematic random sampling was used for sampling technique. The sampling fraction was determined by taking the ratio of households to the sample size i.e.
14. Then, households were selected by using systematic random sampling method by sampling fraction of 14 to get one adult from each house hold. Finally, one eligible adult was selected from each household using simple random sampling/ lottery method if more than one adult was living in the house.

\section{Data collection tool and procedures}

The questionnaire was adapted from previous studies [11, 16-19, 24, 26]. It was initially prepared in English, translated into Amharic (local language) by language experts, and re translated to English to check consistency in meaning of words and concepts. Almost all of the questions were closed ended. The questionnaire consists three parts: socio-demographic or background information, questions to measure clinical characteristics and awareness of glaucoma, sources of information and knowledge of glaucoma. The data were collected through face to face interview by trained data collectors.

\section{Operational definition}

Knowledge: Knowledge was determined based on 12 knowledge questionnaires and was graded as its level (good, poor). All of the questionnaires were closed ended with possible definitions, risk factors and treatment options of glaucoma. Each correct response was given one point. The total score was out of 12 . A score which were $\geq$ $50 \%(\geq 6 / 12)$ were recorded as good knowledge. Otherwise it was recorded as having poor knowledge.

\section{Data management and analysis}

After checking for clarity and completeness data were entered into Epi Info 7 and exported into statistical package for social science/SPSS version 23 for analysis. Both descriptive and analytical methods were employed for analysis. The descriptive parts of the data were summarized using measures of central tendency and dispersion.

Associated factors for knowledge of glaucoma were identified using binary logistic regression. Variables were fitted into the model by using the enter method. The Hosmer and Lemeshow model fitness were used to check model fitness. Multi-collinearity between the independent variables were checked by tolerance and variance inflation factor (V.I.F). Adjusted odds ratio with 95\% confidence level was used to identify the significant factors. Variables with $p$-value of $\leq 0.05$ was considered statistically significant.

\section{Results}

\section{Socio-demographic characteristics}

A total of 594 adults were participated with a response rate of $94.29 \%$. One hundred forty-five 
adults were aware of glaucoma and further asked for knowledge questions. The median (IQR) age was 28 years [22-45]. About 308 (51.9\%) of the respondents were females. Majority 359 (60.4\%) of the participants had no formal education (Table 1).

Table 1 Socio-demographic and socio-economic characteristics of the study participants in Gish Abay town, Northwest Ethiopia, Jun $2018(n=594)$

\begin{tabular}{|c|c|c|}
\hline Characteristics & Frequency & Percent \\
\hline \multicolumn{3}{|l|}{$\overline{\text { Sex }}$} \\
\hline Female & 308 & 51.9 \\
\hline Male & 286 & 48.1 \\
\hline \multicolumn{3}{|l|}{ Age } \\
\hline $18-22$ & 169 & 28.5 \\
\hline $23-27$ & 144 & 24.2 \\
\hline $28-45$ & 140 & 23.6 \\
\hline$\geq 46$ & 141 & 23.7 \\
\hline \multicolumn{3}{|l|}{ Religion } \\
\hline Orthodox & 586 & 98.7 \\
\hline Others* & 8 & 1.3 \\
\hline \multicolumn{3}{|l|}{ Ethnicity } \\
\hline Amhara & 584 & 98.3 \\
\hline Oromo & 10 & 1.7 \\
\hline \multicolumn{3}{|l|}{ Level of education } \\
\hline No formal education & 359 & 60.4 \\
\hline Primary education & 101 & 17.0 \\
\hline Secondary education & 90 & 15.2 \\
\hline College and above & 44 & 7.4 \\
\hline \multicolumn{3}{|l|}{ Marital status } \\
\hline Single & 275 & 46.3 \\
\hline Married & 288 & 48.5 \\
\hline Divorced & 14 & 2.4 \\
\hline Widowed & 17 & 2.9 \\
\hline \multicolumn{3}{|l|}{ Type of occupation } \\
\hline Farmer & 156 & 26.3 \\
\hline Government employee & 48 & 8.1 \\
\hline Merchant & 185 & 31.1 \\
\hline House wife & 72 & 12.1 \\
\hline Job seeker & 64 & 10.8 \\
\hline Others** & 69 & 11.6 \\
\hline \multicolumn{3}{|l|}{ Monthly income } \\
\hline$\leq 750$ & 298 & 50.2 \\
\hline $751-1300$ & 115 & 19.4 \\
\hline $1301-2000$ & 62 & 10.4 \\
\hline$\geq 2001$ ETB & 119 & 20 \\
\hline
\end{tabular}

Others* Muslim and Catholic; Others** $=$ students, driver, religious leader

\section{Knowledge of glaucoma}

About 100 of participants had good knowledge of glaucoma. The proportions of good knowledge of glaucoma were $16.8 \%(14.00,19.9)$.

Factors associated with knowledge of glaucoma.

In the multivariable analysis after adjusting for age, sex, ethnicity, type of occupation chronic diseases either DM or HTN: educational status, level of income, history of eye examination at least once in life and positive family history of glaucoma were significantly associated with good knowledge of glaucoma (Table 2).

\section{Discussion}

The proportion of good knowledge of glaucoma was $16.8 \%(14.0,19.9)$. This finding is lower than reports from Gondar, Northwest Ethiopia (49.6\%) [17]. This might be due to differences in the way we measure knowledge is quite different. In the later study, the level of good knowledge was among aware adults where as in this study it was among all adults participating in the study. This might be also due to the differences in educational status. In the Gondar study about $32.7 \%$ had no formal education as compared to $60.2 \%$ in this study. Previous studies described educational status as the true predictor of knowledge [15-17]. The present finding is also lower than reports from urban Puducherry, India (34\%) [19]. This might be due to the difference in proportion of adults who had history of eye examination (31\%) as compared to $12 \%$ in this study. Previous studies support history of eye examination were directly associated with good knowledge of glaucoma [10, 12, 17].

However, this finding is better than the results reported from Addis Ababa, Capital of Ethiopia (12.1\%) [26], Nigeria, Ebonyi State (6.7\%) [18], Nepal (5.5\%) [27], (1.18\%) [28], urban India, Chennai (0.5\%) [16] and rural India (1.89\%) [24]. This might be due to educational differences among the study participants: about 14.9\% [31] and $12 \%$ [21] as compared to $22.6 \%$ of adults in this study completed higher education.

On the other hand, the finding of the present study is consistent with reports from Tehran, Iran (19.2\%) [25].

In this study, adults with higher educational status were positively associated with good knowledge of glaucoma. This was supported by other studies [15-17]. This might be due to as educational status increases the chance of exposure to health related information transmission increases [19-21, 26].

Adults with positive family history of glaucoma were more likely to had good knowledge of glaucoma. This was supported by different studies [16, 18, 19]. This might be due to the fact that this portion of adults would have personal experience with the challenges of the disease and its treatment options and would help them to acquire knowledge of the condition [18]. 
Table 2 Binary logistic regression of factors associated with knowledge of glaucoma among adults in Gish Abay town, Northwest Ethiopia, Jun 2018 $(n=594)$

\begin{tabular}{|c|c|c|c|c|}
\hline \multicolumn{5}{|c|}{ The level of knowledge of glaucoma } \\
\hline Variables & Good & Poor & COR $(95 \% \mathrm{Cl})$ & AOR $(95 \% \mathrm{Cl})$ \\
\hline \multicolumn{5}{|l|}{ Age category/years } \\
\hline $18-22$ & 22 & 147 & 1.00 & 1.00 \\
\hline $23-27$ & 30 & 114 & $1.75(0.96,3.2$ & $1.51(0.75,3.06)$ \\
\hline $28-45$ & 32 & 108 & $1.97(1.09,3.59)$ & $1.74(0.83,3.67)$ \\
\hline$\geq 46$ & 16 & 125 & $0.85(0.43,1.70)$ & $0.80(0.31,2.05)$ \\
\hline \multicolumn{5}{|l|}{ Sex } \\
\hline Male & 60 & 226 & 1.00 & 1.00 \\
\hline Female & 40 & 268 & $0.56(0.36,0.87)$ & $0.72(0.42,1.22)$ \\
\hline \multicolumn{5}{|l|}{ Educational status } \\
\hline $\begin{array}{l}\text { No formal } \\
\text { education }\end{array}$ & 36 & 323 & 1.00 & 1.00 \\
\hline Primary education & 24 & 77 & $2.79[1.57,4.96]$ & $2.89[1.41,5.90]^{* *}$ \\
\hline $\begin{array}{l}\text { Secondary } \\
\text { education }\end{array}$ & 23 & 67 & $3.08[1.72,5.53]$ & $3.03[1.47,6.24]^{* *}$ \\
\hline College and above & 17 & 27 & $\begin{array}{l}5.64[2.81, \\
11.35]\end{array}$ & $\begin{array}{l}\text { 5.18[2.21, } \\
12.13]^{* * *}\end{array}$ \\
\hline \multicolumn{5}{|l|}{ Income level/ETB } \\
\hline$\leq 750$ & 20 & 278 & 1.00 & 1.00 \\
\hline $751-1300$ & 29 & 86 & $4.68[2.52,8.70]$ & $3.18[1.57,6.42]^{* *}$ \\
\hline $1301-200$ & 15 & 47 & $4.43[2.12,9.27]$ & $3.53[1.54,8.06]^{* *}$ \\
\hline$\geq 2001$ & 36 & 83 & $\begin{array}{l}6.02 \text { [3.31, } \\
10.97]\end{array}$ & $3.11[1.55,6.25]^{* *}$ \\
\hline
\end{tabular}

Eye examination

$\begin{array}{lllll}\text { No } & 63 & 457 & 1.00 & 1.00 \\ \text { Yes } & 37 & 37 & 7.25[4.28, & 6.52[3.37, \\ & & & 12.27] & 12.63]^{* * *}\end{array}$

Chronic diseases

$\begin{array}{lllll}\text { No } & 83 & 468 & 1.00 & 1.00 \\ \text { Yes } & 17 & 26 & 3.68[1.92,7.09] & 1.53[0.62,3.81]\end{array}$

Family history of glaucoma

$\begin{array}{lllll}\text { No } & 83 & 487 & 1.00 & 1.00 \\ \text { Yes } & 17 & 7 & 14.24[5.73, & 12.08[4.13, \\ & & & 35.42] & 35.30]^{* * *}\end{array}$

Where, ${ }^{*} p \leq 0.05 ;{ }^{* *} p \leq 0.01 ;{ }^{* * *} p \leq 0.001 ; 1.00=$ reference; $\mathrm{Cl}$ Confidence Interval, COR crude odds ratio, AOR adjusted odds ratio

Eye examination was another important determinant for knowledge of glaucoma. This was supported with different studies [10, 12, 17]. Higher level of income was positively associated with good knowledge of glaucoma. This was supported with different studies [20-22].

\section{Conclusions}

The proportion of good knowledge of glaucoma was lower. Higher educational status, eye examination at least once in life, positive family history of glaucoma and higher income level were positively associated with good knowledge of glaucoma. This implies that the need for improving this knowledge of glaucoma through community health education programs and also improving regular eye check-up practice to the general population specially to those in the rural parts of the region.

\section{Acknowledgements \\ We would like to acknowledge all participants of the study who kindly volunteered to answer to the interview. Our gratitude also goes to data collectors for their tireless work during data collection.}

\section{Authors' contributions}

ZYB designed and conceptualized the study from proposal development to manuscript writing. AT, YA and FA critically reviewed and add their comments in the paper. All authors read and approved the final manuscript.

\section{Funding}

The study was funded by St. Pauls Hospital Millennium Medical Collage and the funding is specifically for designing of the study, field work, analysis and write up.

\section{Availability of data and materials}

The dataset used and or analysed during this study are available from a corresponding author on a reasonable request from Mr. Zewdu Yenegeta (contact address: zewduyenegeta@gmail.com).

\section{Ethics approval and consent to participate}

Ethical clearance was obtained from University of Gondar, College of Medicine and Health Sciences and Comprehensive Specialized Hospital, School of Medicine Ethical Review Committee and letter of permission was obtained from Gish Abay town Administrative Office. Permission was also gained from each household heads before contacting study participants. Since there were only questionnaires were used for data collection on study participants the ethics committee approved to take only verbal informed consent and it was obtained from each study participant.

All the study participants were informed about the purpose of the study and their right to refuse and withdraw the study at any time. Confidentiality was also maintained by excluding identifiers and using codes. Glaucoma related information was given orally for all study participants after completion of the interview.

\section{Consent for publication}

Not applicable.

\section{Competing interests}

The authors declare that they have no competing interests.

\section{Author details}

'Department of Ophthalmology, St. Paul's Hospital Millennium Medical College, Addis Ababa, Ethiopia. '2Department of Optometry, College of Medicine and Health Sciences, University of Gondar, Gondar, Ethiopia. ${ }^{3}$ Department of Ophthalmology, College of Medicine and Health Sciences, University of Gondar, Gondar, Ethiopia.

Received: 26 January 2019 Accepted: 27 December 2019 T.

\section{References}

1. Simmons ST, Cioffi G, Gross R. Basic and clinical science course, section 10: Glaucoma. 16th ed. San Franscisco: American Academy of Ophthalmology; 2017.

2. WHO. Global data on visual impairment. Geneva: World Health Organization; 2012. [updated 21; cited 2018 10]. Available from: http://www. who.int/about/licensing/copyright_form/en/index.html

3. Tham YC, Li X, Wong TY, Quigley HA, Aung T, Cheng CY. Global prevalence of glaucoma and projections of glaucoma burden through 2040: a systematic review and meta-analysis. Ophthalmology. 2014;121(11):2081-90.

4. Berhane Y, Worku A, Bejiga A, Adamu L, Alemayehu W, Bedri A, et al. Prevalence and causes of blindness and low vision in Ethiopia. Ethiop J Health Dev. 2007;21(3):204-10. 
5. Giorgis AT. Raising public awareness of glaucoma in Ethiopia. Community Eye Health j. 2012;25:46.

6. Cypel MC, Kasahara N, Atique D, Umbelino CC, Alcântara MP, Seixas FS, et al. Quality of life in patients with glaucoma who live in a developing country. Int Ophthalmol. 2004;25(5-6):267-72.

7. Do S, Hans L. Report of the rapid assessment for avoidable blindness in Cambodia. National Program for eye health; 2007.

8. Cristina F, Kafi S, Otavio C, Dave P, Jonathan C, Marcelo H. Burden of disease in patients with glaucoma in Brazil: results from 2011-2012 national health and wellness survey. Milan, Italy; 2015.

9. Nwosu S. Patients' knowledge of glaucomaand treatment options. Niger J Clin Pract. 2010;13(1):74-77.

10. Adegbehingbe BO, Bisiriyu L. Knowledge, attitudes, and self care practices associated with glaucoma among hispital workers in lle-lfe, Osun State, Nigeria. Tanzan J Health Res. 2008;10(4):240.

11. Tenkir A, Solomon B, Deribew A. Glaucoma awareness among people attending ophthalmic outreach services in southwestern Ethiopia. BMC Ophthalmol. 2010;10(1):17.

12. Altangerel U, Nallamshetty HS, Uhler T, Fontanarosa J, Steinmann WC, Almodin JM, et al. Knowledge about glaucoma and barriers to follow-up care in a community glaucoma screening program. Can J Ophthalmol. 2009:44(1):66-9.

13. Kyari F, Abdull MM, Bastawrous A, Gilbert CE, Faal H. Epidemiology of glaucoma in sub-saharan Africa: prevalence, incidence and risk factors, Middle East Afr J Ophthalmol. 2013;20(2):111-25.

14. Livingston PM, Lee SE, De Paola C, Carson CA, Guest CS, Taylor HR. Knowledge of glaucoma, and its relationship to self-care practices, in a population sample. Aust N Z J Ophthalmol. 1995;23(1):37-41.

15. Ntim-Amponsah CT, Winfried MA, Ofosu-Amaah S. Awareness and knowledge of glaucoma and other diseases associated with blindness in a Ghanaian comunity. Niger J Ophthalmol. 2004;12(2):50-4.

16. Sathyamangalam RV, Paul PG, George R, Baskaran M, Hemamalini A, Madan $\mathrm{RV}$, et al. Determinants of glaucoma awareness and knowledge in urban Chennai. Indian J Ophthalmol. 2009;57(5):355-60

17. Alemu DS, Gudeta AD, Gebreselassie KL. Awareness and knowledge of glaucoma and associated factors among adults: a cross sectional study in Gondar town, Northwest Ethiopia. BMC Ophthalmol. 2017;17(1):154.

18. Ogbonnaya CE, Ogbonnaya LU, Okoye O, Kizor-Akaraiwe N. Glaucoma awareness and knowledge, and attitude to screening, in a rural community in Ebonyi State, Nigeria. Open J Ophthalmol. 2016;06(02):119-27.

19. Muthu KV, Baba D, Rathna K, Natarajan S, Divya S. Prevalence of awareness and knowledge of glaucoma in urban Puducherry. Sch J App Med Sci. 2015; 3(7B):2561-7.

20. Faroog S, Jaffar S, Kausar A. Determinants of glaucoma awareness in urban Punjab. Pakistan Armed Forces Med J. 2015;65(5):591-4.

21. Pujar C, Dasar L, Jayshree M, Patil MG, Shirbur PS. Evaluation of the awareness on glaucoma in a rural eye camp in North Karnataka, India. J Clin Diagn Res. 2012;6(7):1226-8.

22. Jin YPMG, Lin K, Trope GE. Glaucoma knowledge in a black community in Toronto. Int J Ophthalmol Eye Res. 2014;2(5):59.

23. Krishnaiah S, Kovai V, Srinivas M, Shamanna BR, Rao GN, Thomas R. Awareness of glaucoma in the rural population of southern India. Indian J Ophthalmol. 2005;53(3):205-8.

24. Rewri P, Kakkar M. Awareness, knowledge, and practice: a survey of glaucoma in north Indian rural residents. Indian J Ophthalmol. 2014;62(4):482-6.

25. Ziaei H, Katibeh M, Panah E, Moein H, Kalantarion M, Hosseini S. Knowledge and awareness of age related eye disease among people over 45 years of age in Tehran: a population-based survey; 2012.

26. Degineh $\mathrm{H}$, Giorgis AT. Glaucoma awareness among ophthalmic patients at Menelik II hospital, Addis Ababa, Ethiopia. Ethiop J Health Dev. 2013;27(3):230-4.

27. Gyawali R, Sarkar N. Glaucoma awareness in a hospital presenting population in eastern Nepal. J Glaucoma. 2014;23(9):594-8.

28. Thapa SS, Berg RV, Khanal S, Paudyal I, Pandey P, Maharjan N, et al. Prevalence of visual impairment, cataract surgery and awareness of cataract and glaucoma in Bhaktapur district of Nepal: the Bhaktapur Glaucoma study. BMC Ophthalmol. 2011;11(1):2.

\section{Publisher's Note}

Springer Nature remains neutral with regard to jurisdictional claims in published maps and institutional affiliations.

\section{Ready to submit your research? Choose BMC and benefit from:}

- fast, convenient online submission

- thorough peer review by experienced researchers in your field

- rapid publication on acceptance

- support for research data, including large and complex data types

- gold Open Access which fosters wider collaboration and increased citations

- maximum visibility for your research: over $100 \mathrm{M}$ website views per year

At $\mathrm{BMC}$, research is always in progress.

Learn more biomedcentral.com/submissions 